\title{
Kesiapan Lapas Kelas I Bandar Lampung Dalam Menghadapi Bencana Alam
}

\author{
Ganda Aulia Wicaksana*, Padmono Wibowo \\ Politeknik Ilmu Pemasyarakatan, Indonesia \\ Jalan Raya Gandul No. 4 Kec.Cinere, Kota Depok, Prov. Jawa Barat, Indonesia \\ *Correspondence email: gandaaulia1@gmail.com, padmonowibowo@gmail.com
}

\begin{abstract}
Abstrak. Keadaan Lembaga Pemasyarakatan di Indonesia yang saat ini sedang over capacity atau kelebihan kapasitas serta Letak geografis Indonesia yang dikelilingi oleh puluhan gunung berapi yang masih aktif juga berada di zona atau area ring of fire yang membuat kondisi negara Indonesia sangat berbahaya dan rawan terjadinya bencana. Namun masih banyak ditemukan kurangnya kesadaran pegawai mengenai kecelakaan kerja dan kurangnya rambu Keselamatan dan Kesehatan Kerja di UPT pemasyarakatan. Sehingga menyebabkan banyaknya terjadi kerusuhan di Lapas karena terjadi bencana. Tujuan penelitian ini membahas mengenai faktor-faktor penyebab kecelakaan di lapas, implementasi jalur evakuasi di lapas dan peninjauan pelaksanaan jalur evakuasi di Lapas. Metode yang digunakan di dalam penelitian ini ialah metode deskriptif dengan pendekatan kualitatif, sumber data yang diperoleh berupa observasi lapangan, wawancara dan studi studi literatur sebagai sumber data sekunder. Penelitian ini dilakukan di Lapas Kelas I Bandar Lampung. Hasil dari penelitian ini yaitu untuk dapat mengetahui faktor-faktor penyebab kecelakaan di lapas, untuk mengetahui implementasi jalur evakuasi di Lapas dan dapat melakukan evaluasi pelaksanaan keselamatan bencana alam maupun bencana yang lainnya berdasarkan hasil implementasi jalur evakuasi di Lapas serta mekanisme pelaksanaan jalur evakuasi sebagai kesiapan suatu Lapas dalam menghadapi, mengantisipasi dan mencegah terjadinya bencana. Penelitian ini membahas mengenai betapa pentingnya pemenuhan rambu keselamatan dan kesehatan kerja berupa jalur evakuasi untuk memberikan rasa aman dan keselamatan dalam bekerja. Penelitian ini juga membahas mengenai pelaksanaan rambu keselamatan dan kesehatan kerja sebagai pemenuhan hak bagi narapidana. Sehingga penelitian ini diharapkan akan membuat pandangan masyarakat mengenai narapidana tidak selalu negatif dan merubah pandangan masyarakat terhadap kehidupan narapidana di Lapas.
\end{abstract}

Kata kunci: keselamatan kerja, kesehatan kerja, jalur evakuasi, bencana, narapidana

\begin{abstract}
The condition of correctional institutions in Indonesia which is currently over capacity or overcapacity as well as the geographical location of Indonesia which is surrounded by dozens of active volcanoes which are also in the zone or ring of fire area which makes the condition of the Indonesian state very dangerous and prone to disasters. However, there are still many lack of employee awareness regarding work accidents and a lack of Occupational Safety and Health signs in the correctional Technical Implementation Unit. So that it caused a lot of riots in the correctional institutions because of the disaster. The purpose of this study discusses the factors that cause accidents in prisons, the implementation of evacuation routes in prisons and a review of the implementation of evacuation routes in prisons. The method used in this research is descriptive method with a qualitative approach, the data sources obtained are field observations, interviews and literature studies. Data collection techniques are direct observation and interviews as primary data and literature studies and theory studies as secondary data. This research was conducted at the Class I Correctional Institution in Bandar Lampung. The results of this study are to be able to find out the factors that cause accidents in prisons, to find out the implementation of evacuation routes in prisons and to be able to evaluate the implementation of safety for natural disasters and other disasters based on the results of implementing the evacuation routes in prisons and the mechanisms for implementing evacuation routes. as the readiness of a correctional institution in dealing with, anticipating and preventing disasters. This study discusses the importance of fulfilling occupational safety and health signs in the form of evacuation routes to provide a sense of security and safety at work. This research also discusses the implementation of occupational safety and health signs as the fulfillment of the rights of prisoners. So that this research is expected to make people's views about prisoners not always negative and change people's views on the life of prisoners in prisons.
\end{abstract}

Keywords: occupational safety and health, evacuation routes, disaster, prisoners

\section{PENDAHULUAN}

Narapidana telah diatur oleh negara untuk mendapatkan haknya seperti warga negara yang lain narapidana mempunyai hak serta kewajiban yang diatur oleh negara, Kepenjaraan merupakan sistem yang berbeda jauh dengan sistem Pemasyarakatan yang memberikan pembinaan bagi narapidananya tetapi sistem kepenjaraan lebih menekankan kepada penjeraan agar tidak mengulangi tindakannya. Sehingga dengan merujuk pada hal itu banyak faktor yang tidak sesuai dengan peraturan perundang-undangan yang berlaku bahkan hal itu tidak sesuai dengan cita-cita Pancasila dan Undang-Undang Dasar 1945. Konsepsi hukum nasional yang berdasarkan Pancasila tidak relevan dan tidak ada hubungannya dengan sistem kepenjaraan. Hal inilah yang menyebabkan Munculnya istilah "Pemasyarakatan" dengan munculnya Pemasyarakatan secara resmi menggantikan istilah "Kepenjaraan" yaitu pada tanggal 27 April 1964, pemasyarakatan pertama kali dicetuskan oleh bapak Dr. Sahardjo menteri kehakiman pada saat itu melalui amanat 
tertulis Presiden Republik Indonesia, yang dilaksanakan pada saat Konferensi Kepenjaraan di Lembang, Bandung. Yaitu Pemasyarakatan merupakan tujuan dari penjara, walaupun sistem Pemasyarakatan sudah menggantikan sistem kepenjaraan tetapi pada pelaksanaannya masih belum dilaksanakan sepenuhnya. Terkhusus yaitu Lapas/Rutan yang merupakan Unit Pelaksana Teknis yang bertujuan untuk memberikan pembinaan dan perawatan kepada para narapidana maupun tahanan.

Fakta yang terjadi pada pelaksanaannya banyak oknum petugas Lapas tindakan yang tidak berintegritas melanggar disiplin, tidak menghiraukan lingkungan kerja serta sarana dan prasarana penunjang tugas yang masih kurang. Pada dasarnya kejahatan terjadi karena kesalahan yang diperbuat dan muncul pada masyarakat itu sendiri. Dengan melakukan pemulihan hubungan pelaku, korban serta masyarakat itu sendiri merupakan pandangan dari konsep Pemasyarakatan dan bukan melihat pelaku kejahatan sebagai orang yang harus dihukum seberat-beratnya tetapi dengan melakukan pembinaan sehingga dapat tercapainya tujuan pemasyarakatan. Telah dituangkan di UndangUndang No. 12 tahun 1995 tentang Pemasyarakatan bahwa kehilangan kemerdekaan merupakan satu-satunya penderitaan ${ }^{1}$. Maka negara tidak berhak mencabut hak narapidana selain pencabutan hak kemerdekaan bergerak dan menambah kesakitan narapidana di dalam menjalani masa pidananya. Menjalani pembinaan di dalam Lapas serta kehilangan kemerdekaan bergerak satu-satunya kesakitan yang hanya dirasakan oleh Narapidana. Sehingga narapidana juga harus tetap mendapatkan perlindungan HAM yang berlaku sesuai dengan perundang-undangan yang ada di Indonesia. Letak geografis indonesia berada dalam 3 lempeng benua yaitu berada di sebelah selatan yaitu Lempeng Indo-Australia yang bergerak ke utara, di sebelah timur oleh Lempeng Pasifik yang bergerak ke arah barat, dan di sebelah utara oleh Lempeng Eurasia yang bergerak ke arah tenggara ${ }^{2}$. Indonesia yang dikelilingi oleh puluhan gunung berapi yang masih aktif juga berada di zona atau area ring of fire ${ }^{3}$.

Kondisi Lapas dan Rutan yang ada di seluruh Indonesia menghadapi beberapa masalah klasik yaitu berupa over capacity atau kelebihan kapasitas penghuni dimana kapasitas untuk menampung narapidana tidak sesuai dengan jumlah narapidana maupun tahanan yang masuk dan bertambah setiap harinya sehingga ketidaksesuaian inilah yang menyebabkan Lapas atau Rutan kelebihan kapasitas dalam menampung penghuninya hal inilah yang menyebabkan sering terjadinya gangguan keamanan dan ketertiban dan rawan terjadinya kecelakaan dalam bekerja serta kerusuhan, kebakaran dan gangguan kamtib lainnya. Sehingga terjadinya kerusuhan akibat dari suatu bencana alam seperti halnya gempa bumi akan menyebabkan narapidana maupun pegawainya dalam keadaan panik dan tertekan untuk menyelamatkan dirinya masing-masing. Sehingga dengan terkait hal tersebut, maka harus adanya pemenuhan HAM sesuai dengan pasal 28 A dan A Undang-Undang Dasar 1945. Yaitu bahwa setiap orang berhak untuk hidup serta berhak mempertahankan hidup dan kehidupannya, sesuai dengan yang tertuang pada pasal 28 A UUD $1945^{4}$.

Bencana adalah suatu peristiwa atau rangkaian peristiwa yang disebabkan oleh berbagai faktor dari alam maupun non alam serta faktor dari manusia, sehingga mengakibatkan timbulnya korban jiwa manusia, kerusakan lingkungan, kerugian harta benda, dan dampak psikologi ${ }^{5}$. Sudah banyak terjadinya kecelakaan akibat bencana alam yang menjadi penyebab kerusuhan di Lapas dan di Rutan yang ada di Indonesia. Terkait dengan hal itu maka harus diciptakan suatu Sistem Manajemen Keselamatan Dan Kesehatan Kerja (SMK3). Pada lingkungan kerja, K3 berguna dan sangat penting dalam menciptakan lingkungan kerja yang aman karena merupakan suatu ilmu yang mempelajari mengenai cara penerapan untuk mengantisipasi/mencegah adanya penyakit atau korban jiwa akibat adanya suatu kecelakaan ${ }^{6}$. Seperti halnya dengan Lembaga Pemasyarakatan dimana narapidana dan pegawai yang bekerja di Lapas merupakan prioritas utama.

Disamping keselamatan dari pegawainya, keselamatan para Warga Binaan Pemasyarakatan juga wajib diperhatikan serta dasar hukum dari pelaksanaan SMK3 yaitu, UU RI No. 1 Tentang Keselamatan Kerja, Dan Permenaker RI No. Per 05/MEN/1996 Tentang Sistem Manajemen Keselamatan Kerja Semua Perusahaan Wajib Melaksanakan SMK3. Terkait dengan hal itu maka teori penyebab terjadinya kecelakaan kerja menurut H.W Heinrich

1 Undang-Undang Republik Indonesia, Undang-Undang Republik Indonesia Nomor 12 Tahun 1995 Tentang Pemasyarakatan., 1995.

${ }^{2}$ Kartono Tjandra, Empat Bencana Geologi Yang Paling Mematikan, ke-1 (Yogyakarta: Gadjah Mada University Press, 2017).

${ }^{3}$ Adam Abraham Wiwaha, Estuning Tyas Wulan Mei, and Rini Rachmawati, 'Perencanaan Partisipatif Jalur Evakuasi Dan Titik Kumpul Desa Ngargomulyo Dalam Upaya Pengurangan Resiko Bencana Gunungapi Merapi’, Journal of Regional and City Planning, 27.1 (2016), 34-48.

${ }^{4}$ undang-undang republik indonesia, Undang-Undang Dasar 1945, 1945.

5 Suratman Worosuprojo and others, 'Prosiding Seminar Nasional Penginderaan Jauh Dan Sistem Informasi Geografis 2012', in Manajemen Bencana Berbasis Informasi Geografis Untuk Mewujudkan Kehidupan Masyarakat Yang Harmonis Dengan Alam Di Indonesia (Surakarta: Muhammadiyah University Press, 2012).

${ }^{6}$ I Ketut Sucita and Agung Budi Broto, 'Identifikasi Dan Penanganan Risiko K3 Pada Proyek Konstruksi Gedung', Poli Teknologi, 10.1 (2011), 83-92. 
pada tahun 1920-an. Yaitu teori domino atau "Lost of Cousation Model" dan rentetan kejadian dari sebelum terjadinya suatu kecelakaan.

Berdasarkan teori dan penjelasan diatas maka penelitian ini dibuat dengan harapan akan berguna bagi masyarakat dan instansi terkait dalam menganalisis dan mengimplementasi dari pelaksanaan program keselamatan yang bukan hanya untuk narapidana tetapi untuk pegawai pemasyarakatan. Terdapat beberapa permasalahan yang akan dibahas di dalam jurnal ini yaitu faktor-faktor apa saja yang menjadi penyebab kecelakaan bencana di lapas kelas I Bandar lampung, Bagaimana implementasi jalur evakuasi di Lapas Kelas I Bandar Lampung dan Peninjauan pelaksanaan keselamatan bencana yang seharusnya terjadi di Lapas Kelas I Bandar Lampung terkait dengan implementasi jalur evakuasi di Lapas Kelas I Bandar Lampung.

Tentunya dengan membahas masalah tersebut penelitian ini akan mempunyai tujuan yaitu Untuk mengetahui faktor-faktor penyebab kecelakaan bencana di Lapas Kelas I Bandar Lampung sehingga dapat mengetahui bagaimana pelaksanaan dan implementasi dari jalur evakuasi sebagai bentuk antisipasi bencana alam di Lapas Kelas I Bandar Lampung dan Melakukan peninjauan evaluasi pelaksanaan keselamatan bencana terkait dengan implementasi jalur evakuasi di Lapas Kelas I Bandar Lampung.

\section{METODE}

Metode yang digunakan dalam penelitian ini yaitu metode deskriptif dengan pendekatan kualitatif sumber data yang diperoleh berupa observasi lapangan, wawancara dan studi literatur. Teknik pengumpulan data dengan observasi langsung dan wawancara sebagai data primer dan studi literatur serta kajian teori sebagai data sekunder. Observasi dan wawancara secara langsung dilakukan peneliti agar mendapatkan informasi secara menyeluruh, dikarenakan peneliti dapat mengamati secara langsung dan menjadi partisipan didalam Lapas. Lokasi penelitian di Lembaga Pemasyarakatan Kelas I Bandar Lampung yang beralamat di Jalan Pramuka No. 12, Kec. Rajabasa, Kel. Rajabasa Pemuka, Kota Bandar Lampung, Provinsi Lampung.

\section{HASIL DAN PEMBAHASAN}

Pelaksanaan manajemen keselamatan kerja sudah dilaksanakan di beberapa instansi, seperti rumah sakit dan proyek pekerjaan bangunan. Rambu rambu K3 merupakan upaya memberikan arah untuk mencegah terjadinya kecelakaan ${ }^{8}$. Pembuatan rambu K3 dibuat dengan ketentuan:

1. Untuk penunjuk arah dan titik kumpul dibuat dengan warna yang cerah dan kontras dengan tembok lapas berguna agar mudah dilihat dan mencolok sehingga mudah dikenali ketika sedang berada dalam situasi atau kondisi yang panik,

2. Untuk warna dari jalur evakuasi dan titik kumpul yaitu warna hijau karena menandakan zona yang aman. Maka dari itu kondisi yang seharusnya terjadi di lapas adalah terdapat pelaksanaan rambu rambu K3.

\section{Penerapan jalur evakuasi di Lembaga Pemasyarakatan kelas I Bandar Lampung Ketentuan dalam pelaksanaan jalur evakuasi di Lapas}

1. Titik kumpul dibagi menjadi 3 :

a. Pertama dimana titik kumpul yang diperuntukkan untuk titik kumpul warga binaan dan regu pengamanan yang sedang piket, yang sedang berada di dalam blok, letak titik kumpulnya berada di lapangan futsal di dalam Lapas.

b. Titik kumpul kedua berada di lapangan apel letaknya di daerah steril, di lapangan upacara bendera, berada setelah pintu kedua di dekat pos Ka. Rupam diperuntukkan untuk pegawai. Digunakan titik kumpul di dalam lapas agar tidak ada warga binaan yang kabur. Digunakan titik kumpul kedua di Lapas agar tidak ada warga binaan yang kabur sehingga titik kumpul kedua hanya diperuntukkan untuk pegawai.

c. Titik kumpul ketiga berada di area parkiran mobil di depan Lapas, titik kumpul ketiga merupakan area steril yang diperuntukkan untuk pegawai dan pengunjung. Letaknya di depan pintu utama Lapas.

2. Titik kumpul dibagi menjadi 3 dengan tujuan :

a. Agar menjaga keamanan dan ketertiban, dalam hal mengantisipasi dari warga binaan kabur dan memanfaatkan keadaan yang membuat petugas lengah dalam melaksanakan tugas.

b. Titik kumpul pertama berada di dalam lapangan futsal untuk mencegah narapidana dapat kabur, titik kumpul kedua diperuntukkan untuk pegawai yang sedang bertugas dan titik kumpul ketiga berada di dalam lapas di area parkiran yang steril diperuntukkan kepada pegawai dan pengunjung yang berada di Lapas.

3. Apabila terjadi bencana susulan yang menyebabkan narapidana harus di evakuasi dari dalam lapas maka akan dievakuasi menuju titik kumpul ketiga sembari menunggu pihak lain agar membantu evakuasi.

\footnotetext{
${ }^{7}$ M P Riswan Dwi Djatmiko, Keselamatan Dan Kesehatan Kerja (Yogyakarta: Deepublish, 2016).
}

${ }^{8}$ Nurkholis Nurkholis and Gusti Adriansyah, 'Pengendalian Bahaya Kerja Dengan Metode Job Safety Analysis Pada Penerimaan Afval Lokal Bagian Warehouse Di PT. ST', Teknika: Engineering and Sains Journal, 1.1 (2017), 11-16. 
4. Pada saat pelaksanaannya mempunyai beberapa hal yang harus diperhatikan :

a. Pada saat pelaksanaannya para pegawai dan narapidana harus dilakukan sosialisasi terlebih dahulu mengenai jalur evakuasi dan titik kumpul, bagaimana pelaksanaannya dan fungsinya dalam mengantisipasi terjadinya kecelakaan pada saat bencana terjadi.

b. Untuk pemasangan penunjuk arah serta titik kumpul harus jelas dan mempunyai gradasi warna yang mencolok dari warna tembok sehingga dapat dilihat dengan jelas ketika pelaksanaan. Pemasangan penunjuk arah serta titik kumpul harus sesuai dan tepat sehingga dapat dilihat pada saat pelaksanaan.

c. Dilakukan beberapa simulasi agar pegawai dan Warga Binaan mengerti mengenai teknis pelaksanaan pada saat terjadi bencana sehingga mereka mengerti fungsi jalur evakuasi sangatlah penting di suatu Unit Pelaksana Teknis Lembaga Pemasyarakatan karena menyangkut keselamatan jiwa orang banyak.

\section{Titik kumpul}

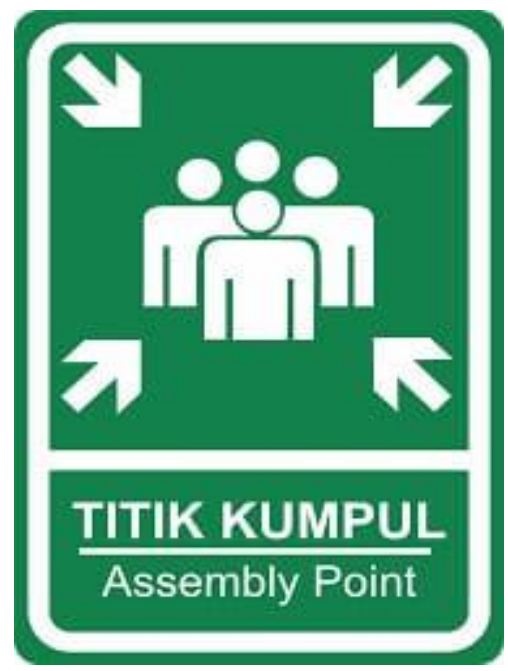

Pengertian titik kumpul sesuai dengan yang dijelaskan Permen PUPR No.14 Tahun 2017 yaitu, Titik kumpul adalah tempat yang bagi pengunjung maupun pengunjung bangunan untuk berkumpul setelah proses evakuasi. Pada pasal 33 ayat (2) pada Permen tersebut menyatakan perancangan dan penyediaan titik kumpul harus memperhatikan:

1. Kesesuaian sebagai lokasi akhir yang dituju dalam rute evakuasi

2. Keamanan dan kemudahan akses pengguna bangunan gedung dan pengunjung bangunan gedung

3. Jarak aman dari bahaya termasuk runtuhan bangunan gedung

4. Kemungkinan untuk mampu difungsikan secara komunal oleh para pengguna bangunan gedung dan pengunjung bangunan gedung

5. Kapasitas titik berkumpul ${ }^{9}$.

Jadi sangatlah penting peran dari titik kumpul agar menjamin keselamatan.dalam mencegah terjadinya kecelakaan saat bencana terjadi.

\section{Jalur evakuasi}
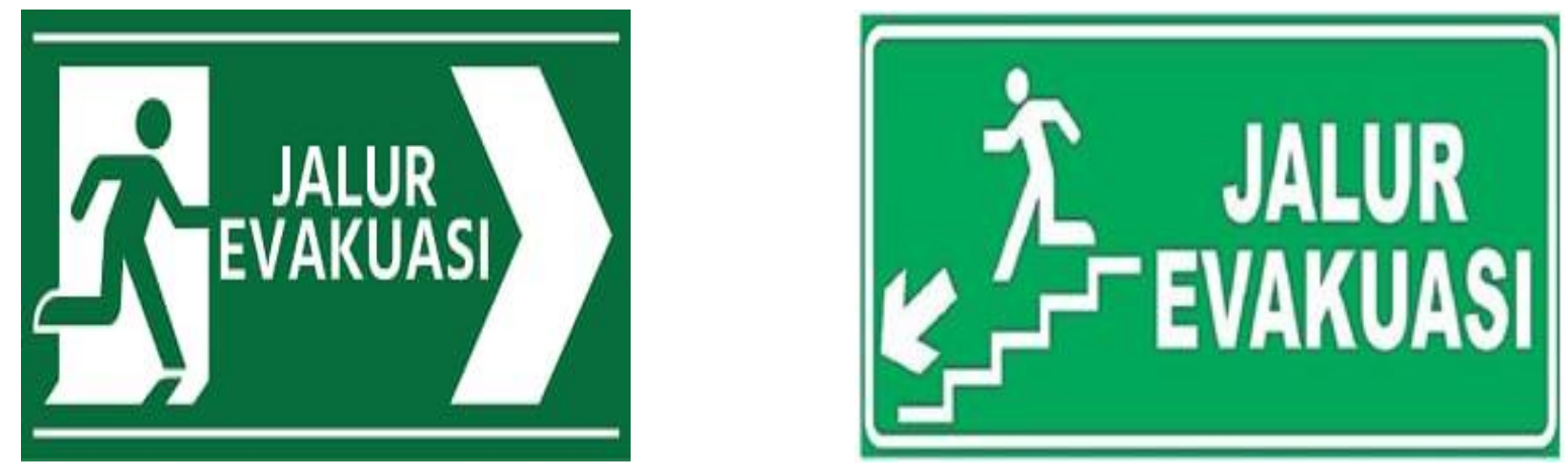

9 Kementrian Pekerjaan Umum dan Perumahan Rakyat, PERATURAN MENTERI PEKERJAAN UMUM DAN PERUMAHAN RAKYAT REPUBLIK INDONESIA NOMOR 14/PRT/M/2O17 TENTANG PERSYARATAN KEMUDAHAN BANGUNAN GEDUNG, 2017. 
Jalur evakuasi mempunyai fungsi yang diperuntukkan untuk menghubungkan dan mengarahkan ke titik kumpul sebagai area atau zona yang aman. Disaat keadaan panik dan darurat bencana, jalur evakuasi menjadi halnya yang sangat dibutuhkan dan penting untuk menunjukkan arah jalur untuk menuju titik kumpul atau area yang aman pada gedung bertingkat, pabrik, rumah sakit tidak maupun Lembaga Pemasyarakatan seperti halnya bencana kebakaran, gempa bumi dan banjir sekalipun. Terkait dengan hal itu maka jalur evakuasi berguna untuk jalur khusus dalam menghubungkan semua area ke area yang aman yaitu titik kumpul.

Dasar hukum yang menjadi peraturan sebagai kewajiban penerapan jalur evakuasi yaitu tertuang pada UU No. 28 Tahun 2002 tentang Bangunan Gedung dan juga Peraturan Pemerintah No. 36 tahun 2005 tentang Bangunan Gedung. Dimana pada PP tersebut menyatakan bahwa "Setiap bangunan gedung, kecuali rumah tinggal tunggal dan rumah deret sederhana, harus menyediakan sarana evakuasi yang meliputi sistem peringatan bahaya bagi pengguna, pintu keluar darurat, dan jalur evakuasi yang dapat menjamin kemudahan pengguna bangunan gedung untuk melakukan evakuasi dari dalam bangunan gedung secara aman apabila terjadi bencana atau keadaan darurat" 10 .

\section{Pelaksanaan jalur evakuasi di Lapas Kelas I Bandar Lampung \\ Faktor-faktor yang menjadi penyebab kecelakaan pada saat bencana di lapas kelas I Bandar Lampung}

Berdasarkan hasil observasi dan wawancara yang dilakukan kepada pegawai dan narapidana terdapat beberapa

faktor-faktor yang menjadi penyebab kecelakaan pada saat bencana di lapas kelas I Bandar Lampung yaitu:

1. Kurangnya kontrol manajemen mengenai keselamatan dan pemahaman pegawai dalam pelaksanaan SOP jalur evakuasi di Lapas Kelas I Bandar Lampung

2. Masih banyak ditemukan pegawai yang belum sadar akan pentingnya rambu-rambu keselamatan di lapas terutama jalur evakuasi dan titik kumpul

3. Pekerjaan pegawai pemasyarakatan yang beresiko, seperti kita ketahui bahwa pegawai dan narapidana mempunyai akses jalur dan ruangan yang berbeda sehingga perlu dibuatkannya penunjuk arah jalur evakuasi.

4. Desain bangunan lapas yang tidak memperhatikan daripada aspek keselamatan sangat mempengaruhi daripada jalur evakuasi dan titik kumpul. Sehingga perlu dibuatkan beberapa titik kumpul di dalam bangunan lapas

5. Belum adanya regulasi yang menjelaskan dan membahas terkait keselamatan dalam lembaga pemasyarakatan baik berupa bencana alam maupun bencana lainnya. Karena ketika terjadi bencana tidak ada regulasi yang mengatur secara jelas akan menyulitkan proses evakuasi dan apabila evakuasi tanpa adanya regulasi akan memperburuk keadaan yang justru mengancam keselamatan narapidana, pegawai dan pengunjung yang berada di lembaga pemasyarakatan.

Dari kondisi sebenarnya, dikaitkan dengan teori domino menurut H.W Heinrich maka hal tersebut sesuai dengan teori penyebab kecelakaan menurut H.W Heinrich yaitu Three Main Factory Theory (Teori Tiga Faktor Utama): Penyebab kecelakaan adalah peralatan, lingkungan dan pekerja itu sendiri. Karena situasi sarana dan prasarana yang tidak mendukung dalam keselamatan di dalam Lembaga Pemasyarakatan, berdampak salah satunya kepada lingkungan yang tidak aman sudah seharusnya di lembaga pemasyarakatan harus diciptakan lingkungan yang sehat dan aman dalam pelaksanaan tugas di Lapas. Serta faktor manusianya yang tidak terlalu peduli dengan keselamatan sehingga membuat pegawainya kurang memahami terkait pelaksanaan jalur evakuasi dan prosedur dalam keselamatan kerja apabila terjadi bencana.

\section{Implementasi jalur evakuasi di Lembaga Pemasyarakatan hasil yang didapat pada saat pelaksanaan jalur evakuasi}

Berdasarkan teori domino menurut H.W Heinrich pada tahun 1920-an. Mengenai akses dapat menjadi pedoman untuk kondisi yang seharusnya (das sollen) dalam penyusunan tata cara evakuasi narapidana. Lapas Kelas I Bandar Lampung masih kurang dalam melaksanakan kontrol manajemen keselamatan. Masih ditemukan belum adanya suatu program maupun sosialisasi yang dibuat dalam menangani pelaksanaan keselamatan dan kesehatan kerja serta tidak adanya SOP dan prosedur yang jelas apabila diterapkan pada saat terjadi suatu bencana.

Di Lapas kelas I Bandar Lampung sendiri masih belum efektifnya pelaksanaan serta difungsikannya jalur evakuasi disebabkan oleh sebab dasar apabila dilihat dengan teori domino yaitu :

1. Peralatan yang masih kurang dan belum memadai seperti halnya sirine dan pengeras suara di setiap blok yang sangat dibutuhkan apabila mengarahkan narapidana untuk menuju titik kumpul saat terjadi suatu bencana. Pintu kamar sel yang masih dibuka secara manual menghambat apabila terjadi suatu bencana di lapas pada saat malam hari atau pada saat steril yaitu jam 18.00 WIB, sehingga menyebabkan narapidana yang ada di kamar akan terjebak dan mengancam keselamatan mereka.

${ }^{10}$ Peraturan Pemerintah Republik Indonesia, PERATURAN PEMERINTAH REPUBLIK INDONESIA NOMOR 36 TAHUN 2005 TENTANG PERATURAN PELAKSANAAN UNDANG-UNDANG NOMOR 28 TAHUN 2002 TENTANG BANGUNAN GEDUNG, 2002. 
2. Masih banyak pegawai yang belum paham penggunaan dan fungsi jalur evakuasi. Perlu adanya diadakan pelatihan bagi pegawai dalam menggunakan jalur evakuasi serta melakukan simulasi apabila suatu saat terjadi bencana di Lembaga Pemasyarakatan.

3. Kebanyakan pegawai dalam melaksanakan pekerjaannya tidak terlalu menghiraukan keselamatan kerja sehingga ini dapat mengancam apabila tiba-tiba terjadi bencana dan dapat dimanfaatkan untuk narapidana dapat kabur.

Pada saat terjadinya suatu bencana tanpa pemahaman regulasi yang benar oleh petugas lapas. Mereka akan menggunakan kebijakan yang apabila tidak tepat justru akan memperburuk keadaan dan mengancam banyak keselamatan. Karena setiap kebijakan akan mempunyai resiko yang besar tanpa mempertimbangkan lingkungan bangunan serta sarana dan prasarana yang ada.

Berdasarkan uraian kondisi keselamatan dan kesehatan kerja yang ada di lapas kelas I Bandar Lampung tersebut terdapat beberapa faktor yang harus dibenahi dan diperbaiki agar menunjang proses keselamatan narapidana, pegawai serta pengunjung. Lingkungan kerja yang baik akan menunjang keselamatan kerja segala aspek. Lingkungan yang tidak aman sangat berpengaruh terhadap terjadinya suatu kecelakaan atau bencana ${ }^{11}$. Sehingga untuk menciptakan lingkungan yang aman dan tertib dibutuhkan kerjasama yang baik serta pemenuhan fasilitas dan pelatihan pegawai.

\section{Evaluasi dan Peninjauan pelaksanaan keselamatan di Lapas Kelas I Bandar Lampung terkait dengan pelaksanaan jalur evakuasi di Lapas Kelas I Bandar Lampung}

Implementasi pelaksanaan keselamatan dan kesehatan kerja adalah suatu kewajiban untuk pemenuhan hak narapidana terkait dengan hak untuk hidup dan hak atas perlindungan pribadi, meskipun narapidana berada di dalam Lembaga Pemasyarakatan negara hanya boleh mencabut hak kemerdekaannya. Rambu-rambu jalur evakuasi dan titik kumpul serta prosedur dalam pelaksanaan evakuasi harus dapat menciptakan lingkungan yang aman. Dengan adanya jalur evakuasi akan memberi keselamatan dan mengurangi resiko terjadinya korban ketika terjadi bencana. Narapidana dan pegawai harus diberikan sosialisasi terkait dengan pelaksanaan jalur evakuasi sehingga pelaksanaan evakuasi dapat berjalan sesuai dengan prosedur. Dilakukannya pelatihan kepada pegawai dengan melibatkan pihak BNPT guna menambah pemahaman dan pengetahuan mengenai apa saja yang harus dilakukan apabila terjadi bencana. Karena kesadaran dalam keselamatan dan kesehatan kerja merupakan faktor yang paling penting dalam pelaksanaan jalur evakuasi. Serta peningkatan fasilitas sarana dan prasarana yang dapat menunjang keselamatan menjadi salah satu penunjang dalam melakukan prosedur keselamatan sehingga dapat mengantisipasi terjadinya kecelakaan saat bencana, baik itu bencana alam maupun bencana kerusuhan ataupun kebakaran dan lainnya. Pemenuhan keselamatan dan kesehatan kerja merupakan bentuk pemenuhan hak narapidana yaitu hak untuk hidup dan hak atas perlindungan pribadi.

\section{SIMPULAN}

Pelaksanaan manajemen keselamatan kerja sudah banyak dilakukan di sejumlah instansi terkait dengan upaya untuk memberikan keamanan dan mencegah terjadinya kecelakaan karena dibuat dengan ketentuan tertentu, dengan membagi titik kumpul menjadi 3 titik kumpul dengan tujuan agar menjaga keamanan dan ketertiban mencegah narapidana untuk kabur serta menjamin keselamatan sehingga harus dilakukan pembagian titik kumpul yang berbeda. Dan apabila diperlukan evakuasi maka mereka akan dikumpulkan di titik kumpul ketiga yang berada di area parkiran lapas yang steril. Sebelum dilakukannya pemasangan jalur evakuasi dan titik kumpul perlu diperhatikan beberapa hal yaitu dengan melakukan sosialisasi kepada narapidana dan pegawai Lembaga Pemasyarakatan, pemasangan rambu jalur evakuasi dan titik kumpul dengan tepat sehingga dapat terlihat dengan jelas dan melakukan simulasi agar implementasinya dapat dimengerti oleh pegawai maupun narapidana. Titik kumpul dan jalur evakuasi adalah keterkaitan yang sangat penting yaitu jalur evakuasi untuk mengarahkan dan menentukan jalur yang tepat untuk menuju ke titik kumpul dimana titik kumpul merupakan area yang aman sehingga dapat terhindar dari kecelakaan saat terjadi bencana.

Berdasarkan pelaksanaannya di Lembaga Pemasyarakatan kelas I Bandar Lampung yaitu, terdapat beberapa faktor yang menyebabkan kecelakaan seperti halnya, kurangnya kontrol manajemen mengenai keselamatan dalam pelaksanaan SOP jalur evakuasi, masih banyaknya pegawai yang belum paham dan sadar akan pentingnya keselamatan kerja di dalam Lapas, pekerjaan yang beresiko di Lapas membuat mudahnya terjadi kecelakaan, desain bangunan yang belum sesuai dalam menghadapi bencana dan belum adanya regulasi yang jelas dan membahas keselamatan dalam Lembaga Pemasyarakatan. Menurut teori domino menurut H.W Heinrich Penyebab kecelakaan adalah peralatan, lingkungan dan manusia pekerja itu sendiri. Pada implementasi jalur evakuasi di Lembaga Pemasyarakatan masih kurang efektif karena sarana dan prasarana yang masih belum terpenuhi, pegawai yang belum

11 Saloni Waruwu and Ferida Yuamita, 'Analisis Faktor Kesehatan Dan Keselamatan Kerja (K3) Yang Signifikan Mempengaruhi Kecelakaan Kerja Pada Proyek Pembangunan Apartement Student Castle', Jurnal Rekayasa Spectrum Industri, 14.1 (2016), 1-108. 
paham dan kesadaran pegawai dalam melaksanakan tugasnya masih kurang sehingga sangat beresiko. Penggunaan kebijakan pada saat terjadi bencana akan beresiko besar karena tidak berpedoman pada ketentuan dan regulasi yang jelas.

Implementasi pelaksanaan keselamatan kerja adalah suatu pemenuhan hak narapidana maka dari itu ini merupakan suatu kewajiban. Perlu diberikannya sosialisasi terkait pelaksanaan jalur evakuasi, pelatihan pegawai dengan melibatkan pihak BNPT, serta meningkatkan fasilitas sarana dan prasarana sebagai penunjang dalam pelaksanaan jalur evakuasi dan keselamatan kerja di Lembaga Pemasyarakatan Kelas I Bandar Lampung.

\section{DAFTAR PUSTAKA}

\section{Buku}

Nurkholis, Nurkholis, and Gusti Adriansyah, 'Pengendalian Bahaya Kerja Dengan Metode Job Safety Analysis Pada Penerimaan Afval Lokal Bagian Warehouse Di PT. ST’, Teknika: Engineering and Sains Journal, 1.1 (2017), $11-16$

Riswan Dwi Djatmiko, M P, Keselamatan Dan Kesehatan Kerja (Yogyakarta: Deepublish, 2016)

Sucita, I Ketut, and Agung Budi Broto, 'Identifikasi Dan Penanganan Risiko K3 Pada Proyek Konstruksi Gedung', Poli Teknologi, 10.1 (2011), 83-92

Tjandra, Kartono, Empat Bencana Geologi Yang Paling Mematikan, ke-1 (Yogyakarta: Gadjah Mada University Press, 2017)

Waruwu, Saloni, and Ferida Yuamita, 'Analisis Faktor Kesehatan Dan Keselamatan Kerja (K3) Yang Signifikan Mempengaruhi Kecelakaan Kerja Pada Proyek Pembangunan Apartement Student Castle', Jurnal Rekayasa Spectrum Industri, 14.1 (2016), 1-108

Wiwaha, Adam Abraham, Estuning Tyas Wulan Mei, and Rini Rachmawati, 'Perencanaan Partisipatif Jalur Evakuasi Dan Titik Kumpul Desa Ngargomulyo Dalam Upaya Pengurangan Resiko Bencana Gunungapi Merapi', Journal of Regional and City Planning, 27.1 (2016), 34-48

Worosuprojo, Suratman, Yuli Priyana, Agus Anggoro Sigit, S Si Jumadi, Aditya Saputra, and S Si Andriyani, 'Prosiding Seminar Nasional Penginderaan Jauh Dan Sistem Informasi Geografis 2012', in Manajemen Bencana Berbasis Informasi Geografis Untuk Mewujudkan Kehidupan Masyarakat Yang Harmonis Dengan Alam Di Indonesia (Surakarta: Muhammadiyah University Press, 2012)

\section{Peraturan dan Perundang - Undangan}

Kementrian Pekerjaan Umum Dan Perumahan Rakyat, Peraturan Menteri Pekerjaan Umum Dan Perumahan Rakyat Republik Indonesia Nomor 14/Prt/M/2017 Tentang Persyaratan Kemudahan Bangunan Gedung, 2017

Peraturan Pemerintah Republik Indonesia, Peraturan Pemerintah Republik Indonesia Nomor 36 Tahun 2005 Tentang Peraturan Pelaksanaan Undang-Undang Nomor 28 Tahun 2002 Tentang Bangunan Gedung, 2002

Undang-Undang Dasar Republik Indonesia 1945

Undang-Undang Republik Indonesia, Undang-Undang Republik Indonesia Nomor 12 Tahun 1995 Tentang Pemasyarakatan., 1995 